\title{
The occurrence and inter-rater reliability of myofascial trigger points in the quadratus lumborum and gluteus medius: a prospective study in non-specific low back pain patients and controls in general practice
}

\author{
Khing Hua Njoo * and Emiel Van der Does \\ Department of Family Medicine. Erasmus Unitersity Rotterdam, 3021 HR Rotterdam (The Netherlands) \\ (Received 16 November 1992, revision received 17 September 1993, accepted 1 February 1994)
}

\begin{abstract}
Summary The presence of a trigger point is essential to the myofascial pain syndrome. This study centres on identifying clearer criteria for the presence of trigger points in the quadratus lumborum and gluteus medius muscle by investigating the occurrence and inter-rater reliability of trigger point symptoms. Using the symptoms and signs as described by Simons' 1990 definition and two other former sets of criteria, 61 non-specific low back pain patients and 63 controls were examined in general practice by 5 observers, working in pairs. From the two major criteria of Simons' 1990 definition only 'localized tenderness' has good discriminative ability and inter-rater reliability (kappa $>0.5$ ). This study does not find proof for the clinical usefulness of 'referred pain', which has neither of these two abilities. The criteria 'jump sign' and 'recognition', on the condition that localized tenderness is present, also have good discriminative ability and inter-rater reliability. Trigger points defined by the criteria found eligible in this study allow significant distinction between non-specific low back pain patients and controls. This is not the case with trigger points defined by Simons' 1990 criteria. Concerning reliability there is also a significant difference between the two different criteria sets. This study suggests that the clinical usefulness of trigger points is increased when localized tenderness and the presence of either jump sign or patient's recognition of his pain complaint are used as criteria for the presence of trigger points in the M. quadratus lumborum and the M. gluteus medius.
\end{abstract}

Key words: Myofascial pain syndrome; Trigger point; Non-specific low back pain; Diagnostic criterium; Reliability; Family practice

\section{Introduction}

Low back pain is a complaint which is usually selflimiting. Diagnostic efforts are aimed at excluding systemic diseases, neurologic conditions or psychosocial distress and not at identifying a specific cause (Deyo 1992). The vast majority $(80-90 \%)$ is classified as nonspecific low back pain. The term non-specific low back pain actually represents the lack of medical knowledge about this heterogeneous group of patients. It is assumed that many of the non-specific low back pain

\footnotetext{
* Corresponding author: Khing Hua Njoo, Department of Family Medicine, Erasmus University Rotterdam, P.O. Box 1738, 3000 DR Rotterdam, The Netherlands. Tel.: (31) 10-408-1111; FAX: (31) $10-425-3338$
}

cases are related to musculoligamentous injury (Haanen 1984; Deyo 1992). Examples of musculoskeletal pain problems are primary fibromyalgia and myofascial pain (Bennett 1990). The focus of this study will be on the myofascial pain syndrome, which Travell $(1983,1992)$ and Simons $(1983,1990)$ have described extensively.

The myofascial pain syndrome is a regional pain complaint (as is low back pain) in the presence of one or more trigger points. Trigger points are considered essential for the myofascial pain syndrome.

Trigger points in the $\mathbf{M}$. iliocostalis lumborum, $\mathrm{M}$. longissimus thoracis, $M$. multifidus, $M$. quadratus lumborum and $M$. gluteus medius (also called the lumbago muscle) are implicated in low back pain. Simons and Travell suggest that trigger points in the $M$. quadratus lumborum and $\mathrm{M}$. gluteus medius are frequently found in low back pain. (Simons 1983; Travell 1992) Also 
these two muscles are more suitable for research because there is a very clear anatomical distinction between them and the muscles are accessible without the necessity of palpation through layers of other muscles or a thick fascia

The identification of a trigger point, however, is a subjective clinical judgement. Simons $(1983,1990)$ and Travell (1983) have published several sets of criteria to establish the presence of an active trigger point. In a recent publication Simons has proposed the following criteria: (1) localized tenderness and (2) referred pain; and, when applicable, (3) a taut, palpable band in the muscle concerned, (4) limited stretch range for the muscle concerned and/or (5) on needling a 'twitch response' (Simons 1990). The first 2 characteristics are present in all other criteria sets ever published by Simons (1983) and Travell $(1983,1992)$ and are therefore considered the major characteristics of a trigger point. Also 'localized tenderness' seems to be considered as a prerequisite of a trigger point; without localized tenderness there is no trigger point. The significance of the other 3 minor characteristics seem to depend on the location of the trigger point or the use of a needle.

A gold standard, i.e., identification of an objective underlying cause for trigger points, is still not available. Studies that have attempted to find pathophysiological evidence for trigger points are not sufficiently solid (Klemp et al. 1982; Hagber 1984; Fricton et al. 1985). Therefore clinical validation at this moment is premature.

The major criticism on the work of Simons and Travell has always been that they have not tested their trigger point symptoms in a controlled study and that the symptoms are too subjective to have strong interrater reliability (Bennett 1990; Nice 1992; Wolfe 1992) This study centres on identifying clearer criteria for the presence of trigger points by investigating the occurrence and inter-rater reliability of trigger point symptoms. The difference in symptom occurrence between patients and controls is interpreted as an indication of the discriminative ability of the specific symptom between 'diseased' and 'non-diseased'. Reliability is measured because only symptoms that prove to be reliable, yield meaningful clinical information. Therefore the 5 clinical characteristics of the proposed criteria in 1990 and 2 other symptoms from former criteria sets (Simons 1983; Travell 1983) are studied in the $M$. quadratus lumborum and $M$. gluteus medius. The aims of the study are: first, to investigate the occurrence of trigger point symptoms in non-specific low back pain patients and in controls; second, to examine inter-rater reliability of the trigger point symptoms in low back pain patients; third, to estimate trigger point occurrence in non-specific low back pain patients and in controls and the inter-rater reliability in low back pain patients.

\section{Material and methods}

\section{Patient population}

The participants were recruited during two consecutive 3 -month periods in the winter of 1989 and spring of 1990 . In the first period, the participants came from one health centre (4 general practitioners) and two private practices ( 2 general practitioners) in a semi-rural area; in the second period they came from one health centre $(5$ general practitioners) in a suburb of Rotterdam. During their office hours the general practitioners invited patients with low back pain and controls to participate in this study.

A total of 16.3 participants ( 81 low back pain patients) were invited to participate in the study. After exclusion of 5 participants ( 4 low back pain patients) who did not meet the study criteria, 158 participants were eligible

The non-response rate was $21 \%$. There were 33 participants $(16$ low back pain patients) who did not make an appointment or did not show up at the appointment and 1 (control) refused to cooperate. On telephone inquiry, it turned out that some participants had returned to work and were not willing to spend spare time on something that had little profit to themselves. The respondents and non-respondents were similar as to gender and age.

Eventually 124 participants entered the study: 61 non-specific low back pain patients and 63 controls. The patients and controls did not differ significantly in age, gender or employment status (Table 1).

\section{Selection criteria}

The participants were selected by the following criteria. (inclusion criteria) age between 20 and 60 years: able to fill in a written questionnaire; (exclusion criteria) concurrent signs of malaise or fever or involuntary weight loss; concurrent cancer; current treatment by a neurologist; a previous operation in the low back region; pathological reflexes and positive straight leg raising test on physical examination by the general practitioner; pregnancy at the time of study; psychiatric history (past and present).

Low back pain patients were patients who had consulted their general practitioner with a recent episode (started less than 2 months ago) of low back pain. The preceding low back pain episode had been at least 3 months (disease-free interval) ago.

The controls were each tenth patient on the appointment list who met the selection criteria, had other reasons than low back pain for consulting their general practitioner and when asked had no low back pain at the time of the consultation.

\section{TABLE I}

BASIC CHARACTERISTICS FOR LOW BACK PAIN PA* TIENTS AND CONTROLS

\begin{tabular}{lll}
\hline Characteristic & $\begin{array}{l}\text { Low back pain } \\
\text { patients } \\
(\mathrm{n}=61)\end{array}$ & $\begin{array}{l}\text { Controls } \\
(\mathrm{n}=63)\end{array}$ \\
\hline Age (years: means and (SD)) & $36.2(9.8)$ & $38.1(9.9)$ \\
Sex (\% female) & 44.2 & 50.7 \\
Employed (numbers) & 46 & 38 \\
$\quad$ Full-time & 38 & 29 \\
Part-time & 8 & 9 \\
Unemployed (numbers) & 15 & 23 \\
Compensation & 6 & 14 \\
Housewife & 9 & 9 \\
Unknown & & 2 \\
\hline
\end{tabular}

All differences are not significant $(P<0.05)$. Age is tested with Student's $t$ test. All other variables are tested with the $\chi^{2}$ test. 


\section{Procedure}

The study was carried out at the participating health centres. The doctor's assistant handed out an information leaflet about the study objectives and protocol, and made appointments with the participants. Most participants were seen directly after their visits to their general practitioners.

The participants answered a semi-structured questionnaire and underwent a standardized physical examination. The questionnaire consisted of sociodemographic and medical history variables. The physical examination consisted of a general (orthopaedic/neurologic) examination for low back pain and the examination of the trigger point symptoms under study. The first observer performed the physical and initial trigger point examination and was aware of the participant's status. The findings were registered on a study form. The trigger point examination was also performed and registered by the second observer who did not know the participant's status. The participant was already positioned on the examination couch at the moment the second observer started the examination.

\section{Trigger point examination}

The following two muscles were examined bilaterally for myofascial trigger points: $T P_{1}, M$. quadratus lumborum: examined with the patient lying on his side with the uppermost arm abducted above his head and his knees bend, with the uppermost knee behind the other knee on the examining table (Travell 1992); and $\mathrm{TP}_{2}, \mathrm{M}$. gluteus medius: examined while the patient was lying prone; in the upper lateral quadrant of the buttock (Travell 1992).

The following symptoms of trigger points were studied. All characteristics except "limited stretch range' were assessed by palpation in the muscles mentioned above: (1) localized tenderness = a spot of maximal tenderness; (2) referred pain $=$ all patterns of referred pain; (3) palpable band = a taut band can be felt in the affected muscle; (4) twitch response $=$ an involuntary contraction of the muscle; (5) limited stretch range = lateral flexion for the quadratus lumborum muscle and adduction for the gluteus medius muscle were tested; (6) jump sign $=$ patient vocalisation or withdrawal; (7) recognition $=$ the patient recognises the pain as his or her pain.

All the characteristics were scored as 'present' or 'absent'. Pain was considered present when the patient labelled the sensation as pain. Referred pain was considered present when any referred pain was experienced by the patient on palpation of the painful spot. The pattern was recorded on a mannequin drawing. Limited stretch range was considered limited when there was a left to right difference.

According to the study protocol the second observer did not

A

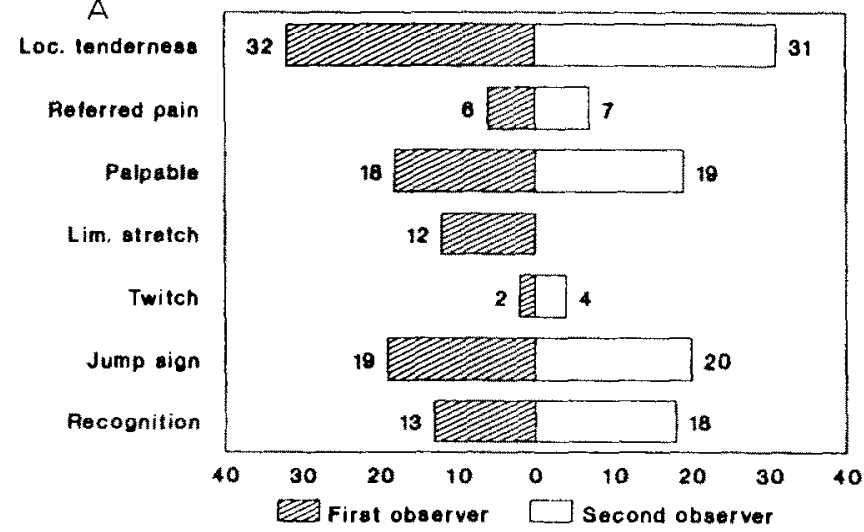

perform the tests for limited stretch range because it required the patient standing up from the examination couch and moving around, thereby unblinding the situation.

\section{Observers}

The observers were an experienced general practitioner (K.N.) who had received additional training in a rheumatology university hospital and medical students who had completed all their internships and were on the threshold of their M.D. Each 3-month period, 2 medical students were trained by the general practitioner. Together with the first author there always was a pool of 3 observers. Any combination of 2 observers could act as the first and second examiner.

\section{Instrumentation}

Prior to the data collection, a pre-study training was performed to ascertain that the observers had similar interpretations of all items of the physical and trigger point examination. The training consisted of the performance, interpretation and registration of the physical and trigger point examination. A force of $\pm 2 \mathrm{~kg}$ applied with the index finger on a balance was trained as standard pressure. The trigger point examinations of pre-study patients were registered independently and compared and evaluated with the test patient present. On the items where the observers disagreed, the patient was examined together. The test patients were also asked to give feedback on which of the observers pressed harder.

During each 3-month period of the study the low back patients were asked to return after 2 and 4 weeks after the first examination to ascertain that the observers still performed similarly. The follow-up sessions were done similar to the pre-study practice examinations.

\section{Statistics}

The occurrence of the trigger point symptom(s) in non-specific low back pain patients is compared with the occurrence in controls. Chi-square statistics are used to detect statistically significant differences $(P<0.05)$

A measure for reliability is kappa. It discounts for the proportion of agreement which is expected by chance alone. This study has selected a kappa of 0.5 as cut-off point of good reliability. The values of inter-rater agreement were calculated on the basis of the observations at the left and right side of the body of low back pain patients. Thus the number of observations was $122(2 \times 61)$.

All the analyses were performed with the Statistical Package for the Social Sciences, version 4.01.

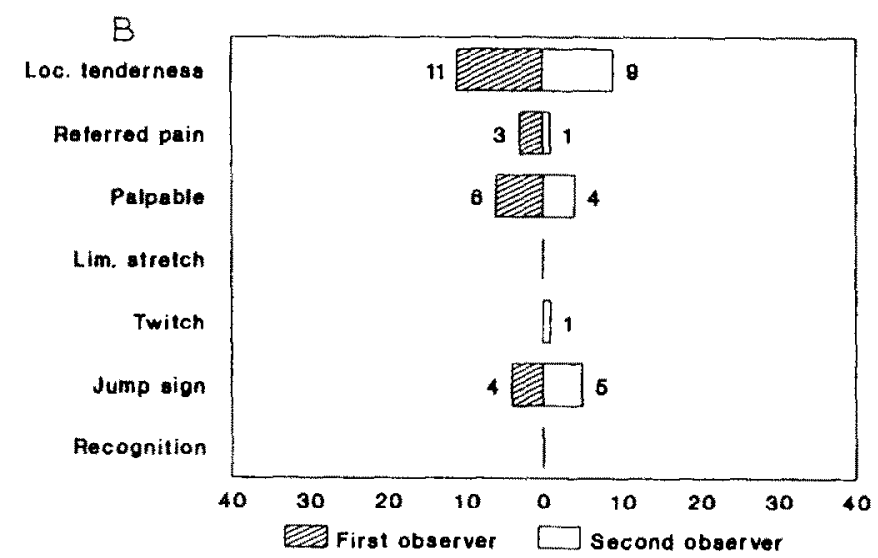

Fig. 1. M. quadratus lumborum. A: LBP patients; B: controls. 
TABLE II

OCCURRENCE OF TRIGGER POINT SYMPTOMS WITHOUT THE PRESENCE OF LOCALIZED TENDERNESS

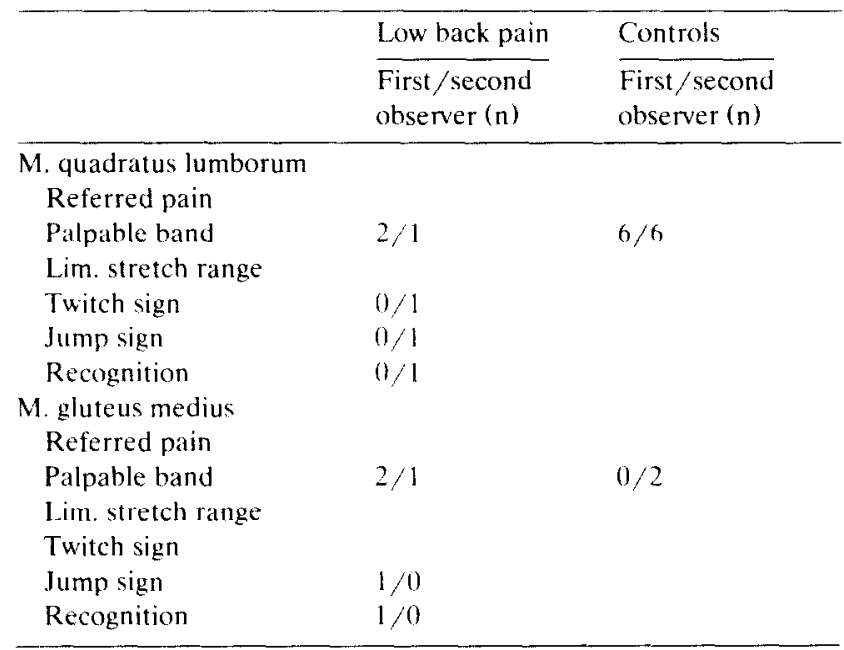

\section{Results}

Occurrence of trigger point symptoms in low back pain patients and controls

First and second observer. The observations of the second blinded observer did not significantly differ from those of the first observer, neither in the low back pain patients nor in the controls (Figs. 1 and 2).

Localized tenderness. Without localized tenderness there is no trigger point, because localized tenderness is a prerequisite of a trigger point. Thus all frequencies displayed are frequencies on condition that localized tenderness was present (Figs. 1 and 2). The frequencies in Table II represent the frequencies without localized tenderness being present. For both muscles palpable band was a sign that seemed to occur without the presence of localized tenderness. In the quadratus lumborum it was even found in a significant number of controls. Except for referred pain some symptoms oc-

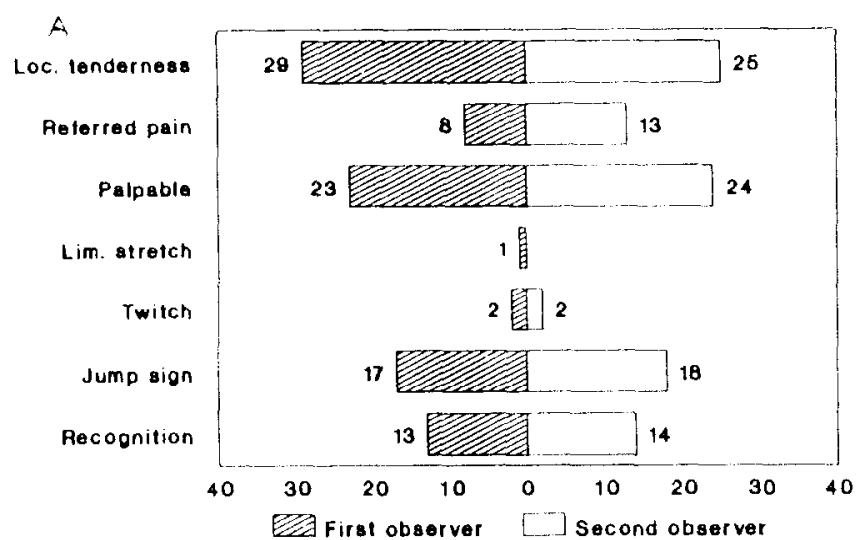

TABLE III

RELIABILITY OF THE TRIGGER POINT SYMPTOMS FOR THE QUADRATUS LUMBORUM AND GLUTEUS MEDIUS MUSCLE

\begin{tabular}{|c|c|c|}
\hline \multirow[t]{2}{*}{$\begin{array}{l}\text { Trigger point } \\
\text { symptoms }\end{array}$} & $\begin{array}{l}\text { M. quadratus } \\
\text { lumborum }\end{array}$ & $\begin{array}{l}\text { M. gluteus } \\
\text { medius }\end{array}$ \\
\hline & Kappa $(95 \%$ CL) & Kappa (95\% CL) \\
\hline Localized tenderness & $0.73(0.61-0.85)$ & $0.58(0.43-0.74)$ \\
\hline Referred pain & $0.36(-0.04 \cdot 0.76)$ & $0.46(0.18-0.74)$ \\
\hline Palpable band & $0.47(0.28-0.68)$ & $0.51(0.34-0.69)$ \\
\hline Twitch sign & $0.19(-0.38-0.77)$ & $-0.02(-0.99-0.96)$ \\
\hline Recognition & $0.57(0.38-1) .78)$ & $0.58(0.38-0.79)$ \\
\hline Jump sign & $0.68(0.53 \cdots(\therefore .83)$ & $0.71(0.55-0.86)$ \\
\hline
\end{tabular}

curred without the presence of localized tenderness in only 1 or 2 persons and always in patients.

Low back pain patients and controls. In both muscles the occurrence of localized tenderness, jump sign, recognition and palpable band was much higher in patients than in controls. Although a difference was found also for referred pain and twitch response, it did not reach statistical significance. Limited stretch range had a higher occurrence only in M. quadratus lumborum.

Inter-rater reliability of the trigger point symptoms

The results in Table III show that localized tenderness, jump sign and recognition in both the quadratus lumborum muscle and the gluteus medius muscle were reliable. Palpable band was only reliable in the $M$. gluteus medius. Twitch response was highly unreliable in both muscles. Because the second observer did not perform the tests for limited stretch range, the interrater reliability of this criterium could not be determincd.

Trigger point occurrence and reliability

If Simons' (1990) major criteria localized tenderness and referred pain were applied, the occurrence of

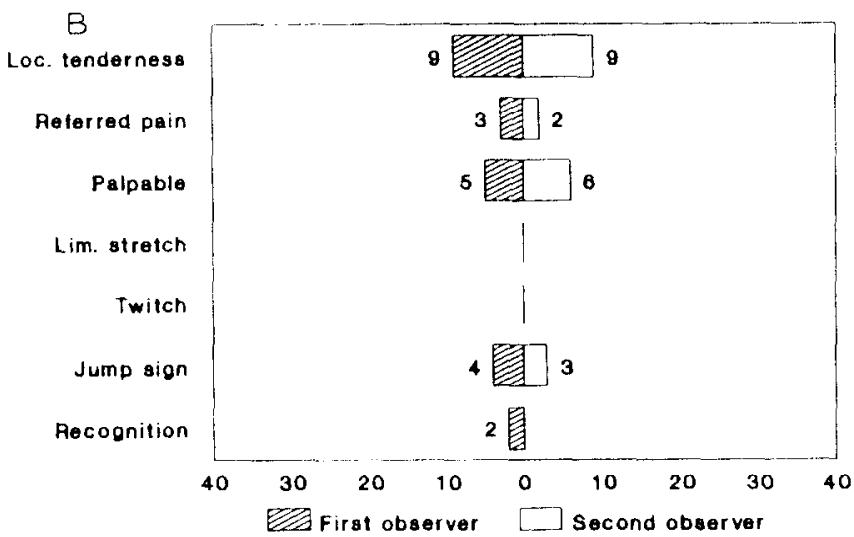

Fig. 2. M. gluteus medius. A: LBP patients; B: controls 
TABLE IV

\section{TRIGGER POINT OCCURRENCE AND RELIABILITY}

Comparison between Simons' 1990 criteria (localized tenderness and referred pain) and criteria found eligible in this study (localized tenderness and (jump sign or recognition).

\begin{tabular}{|c|c|c|c|c|}
\hline Trigger points & $\begin{array}{l}\text { Low back pain } \\
\text { No. of patients }(\%)\end{array}$ & $\begin{array}{l}\text { Controls } \\
\text { No. of patients }(\%)\end{array}$ & $P$ & $\begin{array}{l}\text { Reliability } \\
\text { Kappa (95\% CL) }\end{array}$ \\
\hline \multicolumn{5}{|l|}{ Simons' 1990 criteria } \\
\hline Quadratus lumborum & $6(10 \%)$ & $3(5 \%)$ & NS * & $0.36(0.18-0.74)$ \\
\hline Gluteus medius & $8(13 \%)$ & $3(5 \%)$ & $\mathrm{NS}^{+}$ & $0.46(-0.04-0.76)$ \\
\hline \multicolumn{5}{|l|}{ This study criteria } \\
\hline Quadratus lumborum & $22(36 \%)$ & $4(6 \%)$ & $S^{+}$ & $0.66(0.51-0.81)$ \\
\hline Gluteus medius & $21(34 \%)$ & $4(6 \%)$ & $s^{+}$ & $0.62(0.45-0.79)$ \\
\hline
\end{tabular}

* Fisher exact test (1-tailed), $P<0.05$.

$\chi^{2}$ statistics, $P<0.05$.

trigger points in the quadratus lumborum muscle was 6 $(10 \%)$ in low back pain patients and $3(5 \%)$ in controls and in the gluteus medius muscle $8(13 \%)$ and $3(5 \%)$, respectively. The differences between patients and controls were statistically not significant. The kappa was 0.36 for quadratus lumborum and 0.46 for gluteus medius (Table IV).

\section{Discussion}

\section{Symptom occurrence}

Symptoms are considered signs of disease or pathology when at the best the symptoms are present in patients with the disease and absent in persons without the disease. Trigger point symptoms are described on the basis of observations in clinical practice; the lesion is unknown. Therefore it is unknown which symptoms are pathognomonic and which are accompanying symptoms. The difference in symptom occurrence in patients and controls is interpreted as an indication of the discriminative ability of the specific symptom between diseased and non-diseased. This is the case for localized tenderness, jump sign, recognition and palpable band. Unfortunately, however, palpable band seems to occur without the presence of localized tenderness and often without the presence of pain complaints (Figs. 1 and 2). This raises certain doubts about the specificity of this symptom.

Although a difference in the occurrence between patients and controls can be found for referred pain, it does not reach statistical significance. Twitch response does not reach statistical significance either. In fact it is hardly registered. The occasional presence of the twitch response is not unexpected because according to clinical experience it is not a characteristic that can be found in the two muscles under study (Simons 1990). In various publications different techniques to elicit this response are described: by snapping palpation (Travell 1983; Fricton et al. 1985) or by needling
(Simons 1990) or by pinching or pressing (McCain 1988). The occurrence found in our study is the occurrence when only the pressure technique is used. However, in the sense of clinical significance none of the controls showed this sign. So it can very well be a pathognomonic sign. Other means of establishing this phenomenon like EMG are to be investigated (Fricton 1985).

\section{Inter-rater reliability}

The inter-rater reliability of the physical signs is of great importance when a syndrome has no gold standard. Unreliable symptoms cannot form the core of a clinical syndrome and are preferably left out. In medicine reliability of different diagnostic routines are often unknown or disappointingly low (Sackett 1985) Studies that have investigated the reproducibility of physical signs in low back pain (Nelson 1979; Waddell 1982; McCombe 1989) or of the presence of trigger points (Nice 1992) are no exception to this rule and so is this study. This study arbitrarily has selected a kappa of 0.5 as cut-off point of reliability as a result of this localized tenderness, jump sign and recognition in both the muscles are reliable.

One can object that for the assessment of inter-rater reliability the observers are not equally informed about the patient's status. The first observer could have been biased by the knowledge of the patients low back pain history or the patient's status and could have been tempted to find more characteristics present in the low back pain patients. This is in contradiction with the fact that there are no great differences in the number of observations of the two observers (Figs. 1 and 2). Another objection could be the number of observers and the fact that different combinations of observers were used. This means that the reliability in our study can be considered 'the worst case' estimate. However, this situation resembles the actual situation in clinical practice and, in this respect, represents 'the best possible' result. 
A problem of kappa is that it is very sensitive to small frequencies (Feinstein 1990). For this reason the values of kappa for twitch response and referred pain could have been restricted.

The low reliability level for referred pain can be influenced by the description used in this study: "any referred pain pattern" was registered as present. In literature the descriptions of referred pain vary in different publications. Compare for instance "Characteristic patterns that are specific to individual muscles are referred from myofascial trigger points" (Travell 1983) with "Tender spot must cause referral of pain (or change of sensation) at a distance of at least 2 cm beyond the spot of local tenderness" (Simons 1990). Here it is obvious that a uniform description, preferably validated by clinical research, will probably improve the inter-rater reliability. Unfortunately our data are not suitable to stratify for the different referred pain options.

This study suggests that from the 2 major criteria of Simons' 1990 definition only localized tenderness is clinically useful for the presence of a trigger point in the quadratus lumborum and gluteus medius muscle. Jump sign and recognition are also useful. Unfortunately both symptoms require the patient's reaction or interpretation to the doctor's examination. This suggests that only the presence of either jump sign or recognition is required.

The objective signs that require the doctor's interpretation or point to a potentially underlying cause: twitch response, palpable band and referred pain are not found eligible in this study.

\section{Trigger point occurrence and reliability}

The estimated occurrence (10 and 13\%; Table IV) of trigger points, when Simons' 1990 definition is used is less than the $30 \%$ found in other studies. This could be explained by differences in the location of the pain complaints, the diagnostic criteria used and the study population (Collee et al. 1990; Sootsky 1989; Nice 1992). If the set of criteria found eligible in this study (localized tenderness and jump sign or recognition) is applied, the trigger point occurrence in the quadratus lumborum and gluteus medius muscle is between 34 and $36 \%$ and allows significant distinction between non-specific low back pain patients and controls. This is not the case with Simons' 1990 definition.

Concerning reliability there is a significant difference between the use of Simons' 1990 definition or the set of criteria found eligible in this study. The set of criteria found eligible in this study results in good inter-rater reliability (kappa $>0.6$ ) for the presence of trigger points in the quadratus lumborum and the gluteus medius muscle (Table IV). Nice et al. (1992) have conducted an inter-rater agreement study in the iliocostalis lumborum and the longissimus thoracis muscle in low back pain patients. The definition they have used for the presence of a trigger point ('localized tenderness and referred pain specific for each muscle') resulted in reliability levels that did not exceed a kappa of 0.4 . This is comparable with the reliability levels found in this study for the definition of Simons (1990). In Nice's study the number of observers was much greater (12 physiotherapists) and only one pre-study training session was held (Nice et al. 1992). This stresses the need for multiple training sessions in medical practice and research.

\section{Conclusion}

This study suggests that the clinical usefulness of trigger points is increased when localized tenderness and the presence of either jump sign or patient's recognition of his pain complaint are used as criteria for the presence of trigger points in the $M$. quadratus lumborum and the $M$. gluteus medius.

\section{Acknowledgements}

This project is supported by the Programme for Stimulation of Health Care Research (SGO) of the Dutch Ministry of Welfare, Public Health and Cultural Affairs. The authors wish to express their appreciation to all participating patients, medical students, general practitioners and their practice assistants. The authors also thank F. Bareman, M.Sc., for his support on the data analysis and interpretation of the results, and mrs. de Haan, for her expert review of the English manuscript.

\section{References}

Bennetl, R.M., Myofascial pain syndromes and the fibromyalgia syndrome: a comparative analysis. In: J.R. Fricton and E. Awad (Eds.), Advances in Pain Research and Therapy, Vol. 17, Raven Press, New York, 1990, pp. 43-65.

Collee, G., Dijkmans, B.A.C. Vandenbroucke, J.P., Rozing, P.M. and Cats. A., A clinical epidemiological study in low back pain. Description of two clinical syndromes, Br. J. Rheumatol., 29 (1990) 354-357.

Deyo, R.A. Conservative therapy for low back pain. Distinguishing useful from useless therapy, JAMA, 250 (1983) 1057-1062.

Deyo, R.A., Rainville, J. and Kent, D.L., What can history and physical examination tell us about low back pain?. JAMA, 268 (1992) 760-765.

Feinstein, A.R. and Cicchetti, D.V., High agreement but low kappa. 1. The problems of two paradoxes, J. Clin. Epidemiol., 43 (1990) $543-549$.

Fricton, J.R., Auvinen, M.D., Dijkstra, D. and Schiffman, E., Myofascial pain syndrome: electromyographic changes associated with local twitch response, Arch. Phys. Med. Rehabil., 60 (1985) $314-317$. 
Haanen, H.C.M., Een Epidemiologisch Onderzoek naar Lage Rugpijn, (thesis) Erasmus University, Rotterdam, 1984 (english summary).

Hagberg, M. and Kvarnström, S., Muscular endurance and electromyographic fatigue in myofascial shoulder pain, Arch. Phys. Med. Rehabil., 65 (1984) 522-525.

Klemp, P., Nielsen, H.V., Korsgard, J. and Crone, P., Blood flow in fibromyotic muscles, Scan. J. Rehab. Med., 14 (1982) 81-82.

McCain, G.A. and Scudds, R.A., 'The concept of primary fibromyalgia (fibrositis) clinical value, relation and significance to other chronic musculoskeletal pain syndromes, Pain, 33 (1988) 273-287.

McCombe, P.F., Fairbank, J.C., Cochersole, B.C. et al., 1989 Volvo Award in clinical sciences. Reproducibility of physical signs in low back pain, Spine, 14 (1989) 908-918.

Nelson, M.A., Allen, P., Clamp, S.E. et al., Reliability and reproducibility of clinical findings in low back pain, Spine, 4 (1979) 97-101.

Nice, D.A., Riddle, D.L., Lamb, R.L. et al., Intertester reliability of judgments of the presence of trigger points in patients with low back pain, Arch Phys. Med. Rehab., 73 (1992) 893-898.

Sackett, D.L., Haynes, R.B. and Tugwell, P., Clinical Epidemiology. A Basic Science for Clinical Medicine, Little and Brown, Boston, 1985.

Simons, D.G., Muscular pain syndromes. In: J.R. Fricton and E.
Awad (Eds.), Advances in Pain Research and Therapy, Vol. 17, Raven Press, New York, 1990, pp. 1-41.

Simons, D.G., Travell, J.G., Myofascial origins of low back pain. 1. Principles of diagnosis and treatment, Postgrad. Med., 73 (1983) $66-77$.

Sootsky, S.A., Jaeger, B. and Oye, R.K., Prevalence of myofascial pain in general internal medicine practice, West. J. Med., 151 (1989) $157-160$

Travell, J.G. and Simons, D.G., Myofascial pain and dysfunction. The Trigger Point Manual, Vol. 1, The Upper Extremities, Williams and Wilkins, Baltimore, MD, 1983.

Travell, J.G. and Simons, D.G., Myofascial pain and dysfunction. The Trigger Point Manual, Vol. 2, The Lower Extremities, Williams and Wilkins, Baltimore, MD, 1992.

Waddell, G., Main, C.J., Morris, E.W. et al., Normality and reliability in the clinical assessment of backache, Br. Med. J., 284 (1982) $1519-1523$.

Wolfe, F., Simons, D.G., Fricton, J., Bennett, R.M., Goldenberg, D.L., Gerwin, R., Hathaway, D., McCain, G.A., Russell, I.I., Sanders, H.O. and Sootsky, S.A., The fibromyalgia and myofascial pain syndromes: a preliminary study of tender points and trigger points in persons with fibromyalgia, myofascial pain syndrome and no disease, J. Rheumatol., 19 (1992) 944-51. 